\title{
Clinical and Socio-demographic Determinants of Self-care Maintenance, Monitoring and Management in US Adults with Type 2 Diabetes Mellitus
}

\author{
Michela Luciani, RN, MSN, PhD' (i), Emanuela Rossi, PhD², \\ Paola Rebora, PhD ${ }^{2}$ iD, \\ Michael Stawnychy, MSN, CRNP, PhD student ${ }^{3}$ iD, \\ Davide Ausili, RN, MSN, PhD' (ID, \\ and Barbara Riegel, RN, PhD, FAHA, FAAN ${ }^{3}$
}

\begin{abstract}
The aims of this study were to describe self-care in US T2DM patients and to identify clinical and sociodemographic determinants of self-care maintenance, monitoring, and management in US T2DM patients. A secondary analysis was performed using data from a cross-sectional study done to test the psychometric performance of the Self-Care of Diabetes Inventory in US English speaking adults with diabetes. In our sample $(n=207)$, self-care maintenance was adequately performed (median $=75)$, self-care monitoring was borderline (median $=67.6)$ and self-care management was poor $($ median $=55.6)$. Low income $(p=.0019)$ and low self-care confidence $(p<.0001)$ were associated with relatively lower self-care maintenance. Not taking insulin $(p=.0153)$ and low self-care confidence $(p<.000 \mathrm{I})$ were associated with relatively low self-care monitoring. Low self-care confidence $(p<.000 \mathrm{I})$ was associated with low self-care management. Self-care confidence is a strong determinant of self-care. Interventions designed to improve self-care confidence are urgently needed.
\end{abstract}

\section{Keywords}

type 2 diabetes mellitus, self-care, self-management, self-efficacy

\section{Introduction}

Diabetes is considered one of the health emergencies of the 21 st century, affecting 425 million people worldwide (International Diabetes Federation, 2017). In the United States (US) its prevalence is around $13 \%$, with about 30 million people currently living with diabetes (International Diabetes Federation, 2017). Type 2 diabetes mellitus (T2DM), accounting for $90 \%$ of these cases (International Diabetes Federation, 2017), is associated with macro and microvascular complications such as cardiovascular disease, nephropathy, neuropathy, retinopathy, stroke and cerebrovascular disease (Alberti \& Zimmet, 1998; Hardigan et al., 2016; International Diabetes Federation, 2017). These complications can be seriously debilitating, lowering quality of life (International Diabetes Federation, 2017; Scollan-Koliopoulos et al., 2013) and imposing a huge personal burden (Bommer et al., 2017; International Diabetes Federation, 2017). The economic burdens to individuals and society are also staggering; in the US, each person with diabetes expends around 11,638 USD per year, for a total annual expenditure of 348,274 million USD (International Diabetes Federation, 2017).

Self-care is a key component for managing diabetes (Powers et al., 2017; Song, 2010). Self-care is defined as the process of maintaining health through health promoting practices and managing illness (Riegel et al., 2012, p. 195, 2018). Self-care in T2DM has been shown to reduce hemoglobin

\footnotetext{
'Department of Medicine and Surgery, University of Milano - Bicocca, Monza, Italy

${ }^{2}$ Department of Medicine and Surgery, Centre of Biostatistics for Clinical Epidemiology, University of Milano - Bicocca, Monza, Italy

${ }^{3}$ School of Nursing, University of Pennsylvania, Philadelphia, PA, USA

Corresponding Author:

Davide Ausili, Assistant Professor of Nursing Science, Department of Medicine and Surgery, University of Milano- Bicocca, Via Cadore 48, Monza, 20900, Italy.

Email: davide.ausili@unimib.it
} 
A1c (Powers et al., 2017; Song, 2010), complications (Ausili et al., 2017b), hospitalization (Powers et al., 2017; Song, 2010; Song et al., 2012) and, consequently, costs, while improving quality of life (Ausili et al., 2017b; Powers et al., 2017; Song, 2010) and psychosocial outcomes (Powers et al., 2017). Theoretically, self-care is composed of three core processes: self-care maintenance, self-care monitoring and selfcare management (Riegel et al., 2012, p. 195, 2018). Self-care maintenance focuses on maintaining health and preventing the worsening of symptoms (e.g., adherence to medications, nutrition, exercise, etc.), self-care monitoring involves body listening and other processes designed to detect and interpret changes, and self-care management is done to effectively treat those changes in signs and symptoms (Riegel et al., 2012, p. 195, 2018). A fourth factor known to influence selfcare is self-care confidence (Ausili et al., 2018; Caruso et al., 2019). Self-care confidence is the confidence in one's ability to perform self-care and persist in self-care despite barriers (Riegel et al., 2012).

Knowing determinants of self-care in the T2DM population can help identify people at risk for poor self-care and direct the development of tailored interventions. Previous studies investigating determinants of self-care in T2DM focused on a single behavior (Bonner et al., 2016; Karimy et al., 2016; Koponen et al., 2017) or were performed without an organizing theoretical framework (Clark \& Utz, 2014; Walker et al., 2014). The only study of determinants of selfcare in T2DM with a comprehensive approach guided by a theoretical framework was done in an Italian population (Ausili et al., 2018). In that study, age was associated with self-care maintenance, time from diagnosis with self-care monitoring, employment status with self-care maintenance and self-care management, and economic status with selfcare maintenance and self-care management (Ausili et al., 2018). Age and self-care confidence were associated with self-care maintenance, self-care monitoring and self-care management (Ausili et al., 2018).

As that study (Ausili et al., 2018) was performed in Italy and determinants of self-care are intrinsically linked with socio-cultural conditions and health systems organization and resources (Osokpo \& Riegel, 2019), it is important to study determinants in other contexts. To address these gaps, the aims of this study were to: 1) describe self-care maintenance, monitoring, management and confidence in a US sample of adults with T2DM; and 2) identify clinical and sociodemographic determinants of self-care maintenance, monitoring, and management in US patients with T2DM.

\section{Methods}

We conducted a cross-sectional study with the aim of testing the psychometric performance of the Self-Care of Diabetes Inventory (SCODI) (Ausili et al., 2017a) in US English speaking patients with diabetes (Ausili et al., 2019). This study was a secondary analysis of data coming from that primary cross-sectional study. Participants were enrolled from two acute care hospitals in northeastern US and ResearchMatch.org. The Institutional Review Board of the University of Pennsylvania approved the study after expedited review. Informed consent was provided by each participant.

\section{Sample}

Hospitalized individuals with a diagnosis of diabetes were eligible to participate if they were at least 18 years of age. Exclusion criteria were cognitive impairment and an inability to participate due to poor hearing, inability to read or speak English. In addition, 79 volunteers from ResearchMatch.org responded to our online invitation to complete the SCODI and the sociodemographic survey if they had diabetes. ResearchMatch.org is an electronic, web-based registry of a large population of volunteers who have consented to be contacted by researchers about health studies. The registry is supported by the U.S. National Institutes of Health as part of the Clinical Translational Science Award program. After obtaining Institutional Review Board approval of the study, we posted an invitation on ResearchMatch.org and obtained data from anyone willing to provide it.

\section{Measurement}

Self-care maintenance, monitoring, management and confidence were measured by the SCODI (Ausili et al., 2017a) and were defined above. Self-care maintenance is thought to be mastered before self-care monitoring and management. That is, the three self-care behavior types are thought to be mastered in sequence (Riegel et al., 2012). Self-care confidence, also called self-care self-efficacy, is one's confidence in the ability to perform self-care and continue self-care despite barriers (Riegel et al., 2012). It has been shown to be a strong determinant of self-care in previous studies in diabetes (Ausili et al., 2018; Caruso et al., 2019).

Each of the four scales of the SCODI provides a standardized 0-100 score. Higher scores indicate better self-care and a score of $\geq 70$ is considered adequate self-care (Ausili et al., 2017a). Each of the four scales of the SCODI showed good to excellent psychometric properties. For example, the reliability index ranged from 0.81 (self-care maintenance) to 0.89 (self-care confidence) (Ausili et al., 2017a). The SCODI's validity was also demonstrated by the significant associations with $\mathrm{HbA1c}$, BMI, and complications (Ausili et al., 2017a). Furthermore, the instrument was recently tested for invariance between the Italian and USA population, demonstrating a cross-country measure equivalence (Ausili et al., 2019). In addition, we administered a sociodemographic survey measuring age, sex, ethnicity, marital status, adequacy of family income, employment, and education. We asked how long the participant had diabetes and about their comorbid conditions, medications (insulin or oral blood 
glucose lowering medications only) and the presence of diabetes complications (diabetic retinopathy, diabetic foot, diabetic neuropathy, and diabetic kidney disease).

\section{Data Analysis}

Demographic and clinical characteristics were described by means or median and interquartile range (IQR), for continuous variables, and frequency and percentage, for qualitative variables, accounting only for present data. Score distributions were represented by means of boxplot, median and IQR.

Given the non-normal distribution of the self-care scales, to evaluate which were the determinants of each score, quantile regression was adopted to regress the median of scales scores on the collected patient information. Thus, the parameter estimated by the model is interpreted as an increment of the median (instead of the usual mean), for each unit increment in the independent factors. The regression parameters were estimated by the algorithm Simplex because of the small number of subjects and independent variables included in the models. Confidence intervals and p-values were estimated using the Sparsity function and assuming that the errors in the linear model are independent and identically distributed. P-values were considered statistical significant if lower than 0.05 .

\section{Results}

Of the 207 T2DM patients enrolled, $43.7 \%$ were females. The median age was 61 years old (interquartile range: 55.0 $68.0)$. Most were married or partnered (57.4\%) and fewer than $30 \%$ were educated at the college level or higher. The majority of participants were White/Caucasian (66.7\%), followed by Black/African American (28\%), and Asian (2.4\%).

More than $60 \%$ was unemployed or retired and $17 \%$ reported a low family income that was perceived as inadequate to meet needs. The median time from the diagnosis of T2DM was 13 years (interquartile range: $6.0-20.0$ ), $50 \%$ had at least one diabetes-related microvascular complication, and $75 \%$ had 3 or more comorbidities. The most prevalent comorbidities were hypertension (75.6\%) and heart failure $(67.4 \%)$. Sociodemographic and clinical characteristics of the study sample are shown in Table 1.

Self-care maintenance was performed adequately by the study participants (median $=75$; interquartile range: 66.7-85.4). Self-care monitoring was borderline in adequacy (median $=67.6$; interquartile range: $50.0-85.3$ ) and self-care management was poor (median $=55.6$; interquartile range: 41.7-72.2). Patients reported high confidence in their ability to perform adequate self-care behaviors as shown by their self-care confidence scores (median $=81.8$; interquartile range: 65.9-93.2). Box-plots representing the self-care maintenance, monitoring, management and confidence distributions are reported in Figure 1.
Together, having a low income $(p=.0019)$ and low selfcare confidence $(p<.0001)$ were associated with relatively lower self-care maintenance (Table 2). Not taking insulin $(p=.0153)$ and having low self-care confidence $(p<.0001)$ were associated with relatively lower self-care monitoring (Table 3$)$. Having low self-care confidence $(p<.0001)$ was associated with low self-care management (Table 4).

\section{Discussion}

The purpose of this study was to describe self-care maintenance, monitoring, and management and to identify the clinical and sociodemographic factors associated with the core self-care dimensions of maintenance, monitoring and management in US T2DM patients. The profile of patients was not appreciably different from other chronically ill patient populations: older adults with multiple chronic conditions. Their self-care profile also was typical in that they were best at self-care maintenance and worst at self-care management. Additionally, we found no effects of gender or education on diabetes self-care management, which is consistent with previous results (Rosland et al., 2010).

The most striking result in this analysis was the powerful effect of self-care confidence on self-care behavior. Confidence or self-efficacy was a determinant of self-care maintenance, monitoring, and management. These results are similar to other studies on diabetes (Ausili et al., 2017a) and heart failure (Irani et al., 2019) self-care, suggesting that interventions designed to improve self-care self-efficacy have a strong potential for improving self-care. For example, a recent randomized controlled trial utilizing self-efficacy theory targeted and improved both self-efficacy and hemoglobin A1c (Wichit et al., 2017). Furthermore, a recent systematic review and meta-analysis of self-efficacy interventions found evidence for the effects of self-efficacy on self-management behaviors and glycemic control (Jiang et al., 2019).

Bandura separated self-efficacy into self-efficacy expectations and outcome expectations (Bandura, 1977). Efficacy expectations are defined as "the conviction that one can successfully execute the behavior required to produce the outcomes" (Bandura, 1977). Of the two, self-efficacy expectation is thought to be the main predictor of behavior (Bandura, 1977). Research on self-efficacy has found significant positive correlations with health outcomes such as reduced depression, increased physical functioning, improved health promotion (Eller et al., 2018). Higher levels of diabetes selfefficacy are associated with and predict better diabetes selfmanagement (Jiang et al., 2019; McEwen et al., 2017) and glycemic control (Elissen et al., 2017).

Not all research supports the mediating effects of selfefficacy, however. Studies on self-efficacy interventions to increase physical activity in older adults showed improvements in physical activity without increases in self-efficacy expectations (Resnick, 2013). These results need further clarification as they may have been due to measurement 
Table I. Sociodemographic and Clinical Characteristics of the Sample $(n=207)$.

\begin{tabular}{|c|c|}
\hline & Type 2 \\
\hline Characteristics & $\mathrm{N}(\%)$ \\
\hline Age (median, IQR) & $61.0(55.0-68.0)$ \\
\hline \multicolumn{2}{|l|}{ Gender $(n=206)$} \\
\hline Male & $116(56.3)$ \\
\hline Female & $90(43.7)$ \\
\hline \multicolumn{2}{|l|}{ Ethnicity } \\
\hline Asian & $5(2.4)$ \\
\hline Black/African American & $58(28.0)$ \\
\hline White/Caucasian & I 38 (66.7) \\
\hline Other (e.g., Native American) & $6(2.9)$ \\
\hline \multicolumn{2}{|l|}{ Marital Status $(n=204)$} \\
\hline Divorced, separated, or widowed & $47(23.0)$ \\
\hline Married or partnered & II 7 (57.4) \\
\hline Single, never married & $40(19.6)$ \\
\hline \multicolumn{2}{|l|}{ Education $(n=206)$} \\
\hline High School Graduate or below & $54(26.2)$ \\
\hline Some College (Associate's, Vocational, etc) & $71(34.5)$ \\
\hline College Educated & $41(19.9)$ \\
\hline Master's Degree and above & $40(19.4)$ \\
\hline \multicolumn{2}{|l|}{ Employment Status $(n=173)$} \\
\hline Full or part time & $57(32.9)$ \\
\hline Unemployed or Retired & $116(67.1)$ \\
\hline \multicolumn{2}{|l|}{ Income $(n=205)$} \\
\hline Comfortable; have more than enough to make ends meet & $77(37.6)$ \\
\hline Have enough to make ends meet & $93(45.4)$ \\
\hline Do not have enough to make ends meet & $35(17.1)$ \\
\hline \multicolumn{2}{|l|}{ Diabetes } \\
\hline Years with diabetes (median, IQR) $(n=203)$ & $13.0(6.0-20.0)$ \\
\hline Total Complications (median, IQR) $(n=135)$ & $1.0(0.0-2.0)$ \\
\hline Diabetic Foot & $32(23.7)$ \\
\hline Neuropathy & $61(45.2)$ \\
\hline Retinopathy & $33(24.4)$ \\
\hline Nephropathy & $39(28.9)$ \\
\hline \multicolumn{2}{|l|}{ Clinical Characteristics } \\
\hline Total Diseases (median, IQR) $(n=135)$ & $5.0(3.0-6.0)$ \\
\hline Hypertension & $102(75.6)$ \\
\hline Heart Failure & $91(67.4)$ \\
\hline Arthritis & $63(46.7)$ \\
\hline Kidney Disease & $57(42.2)$ \\
\hline Pulmonary Disease (asthma, emphysema, lung disease) & $29(21.5)$ \\
\hline
\end{tabular}

errors, instrument design, and ceiling effects (Resnick, 2013). In contrast, a diabetes self-efficacy intervention improved self-care, self-efficacy and glycemic control (Tan et al., 2018). Comparing results across studies is challenging, however, as studies utilize multiple methods for evaluating selfcare and self-efficacy. Considering that studies utilizing the SCODI have obtained similar results (Ausili et al., 2017a, 2018; Caruso et al., 2019), the current results are reassuring and lend further support for the importance of self-care efficacy.

The results of this study have implications for future self-care interventions targeting self-efficacy. Effective interventions such as family-based diabetes self-care have been largely successful in improving self-efficacy (Baig et al., 2015). Moreover, improvements in behavior through enhanced self-efficacy may generalize to behaviors that were 


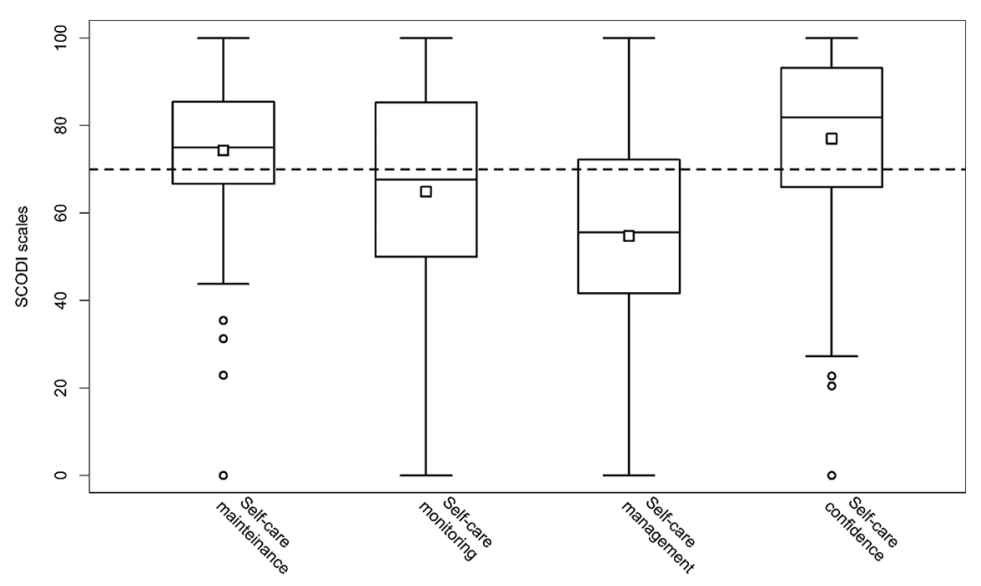

Figure I. Box-plots representing self-care maintenance, monitoring, management and confidence distributions.

Note. The box represents the first and third quartiles, the central line the median, the white square the mean, and the whiskers are located at the maximum and minimum observation if these are in the range of $1.5 \times$ interquartile range from the box. Outside observation is indicated with dots. Dashed line represents the cut-off level of 70 points.

Table 2. Clinical and Sociodemographic Determinants of Self-care Maintenance.

\begin{tabular}{|c|c|c|c|c|c|c|}
\hline Variable & Direction & Estimate & Standard Error & \multicolumn{2}{|c|}{ 95\% Confidence Limits } & $\operatorname{Pr}>|t|$ \\
\hline Gender & Female versus Male & 2.2377 & 2.0127 & -1.7340 & 6.2093 & 0.2677 \\
\hline Age & Age $<60$ versus $A g e \geq 60$ & -0.2315 & 2.1747 & -4.5227 & 4.0598 & 0.9153 \\
\hline Ethnicity & White/Caucasian versus Others & 0.0772 & 2.1124 & -4.0913 & 4.2456 & 0.9709 \\
\hline Income & Low versus Adequate or High & -8.4105 & 2.6640 & -13.6675 & -3.1535 & 0.0019 \\
\hline $\begin{array}{l}\text { Years from the } \\
\text { diagnosis }\end{array}$ & $<10$ years versus $\geq 10$ years & 0.0000 & 2.1672 & -4.2766 & 4.2766 & 1.0000 \\
\hline Education & $\begin{array}{l}\text { High school or lower versus } \\
\text { College or Higher }\end{array}$ & -2.0062 & 2.3366 & -6.6170 & 2.6047 & 0.3917 \\
\hline Medications & No insulin versus Insulin & -0.2315 & $2.63 \mid 4$ & -5.4240 & 4.9611 & 0.9300 \\
\hline Self-care confidence & & $0.44 \mid 4$ & 0.0474 & 0.3478 & 0.5350 & $<.0001$ \\
\hline
\end{tabular}

Table 3. Clinical and Sociodemographic Determinants of Self-care Monitoring.

\begin{tabular}{|c|c|c|c|c|c|c|}
\hline Variable & Direction & Estimate & Standard Error & $95 \%$ Confi & ce Limits & $\operatorname{Pr}>|t|$ \\
\hline Gender & Female versus Male & 0.8216 & 3.1102 & $-5.3|5|$ & 6.9584 & 0.7919 \\
\hline Age & Age $<60$ versus Age $\geq 60$ & -4.6797 & 3.3354 & -11.2607 & 1.9013 & 0.1623 \\
\hline Ethnicity & White/Caucasian versus Others & 1.0360 & 3.2908 & -5.4572 & 7.5291 & 0.7533 \\
\hline Income & Low versus Adequate/High & 2.5006 & 4.0934 & -5.5760 & 10.5772 & 0.5420 \\
\hline $\begin{array}{l}\text { Years from the } \\
\text { diagnosis }\end{array}$ & $<10$ years versus $\geq 10$ years & -4.4773 & 3.3088 & -11.0059 & 2.0514 & 0.1777 \\
\hline Education & $\begin{array}{l}\text { High school or lower versus } \\
\text { College or Higher }\end{array}$ & 1.2979 & 3.6022 & -5.8095 & 8.4053 & 0.7190 \\
\hline Medications & No insulin versus Insulin & -10.1810 & 4.1589 & -18.3869 & $-|.975|$ & 0.0153 \\
\hline Self-care confidence & & 0.7702 & 0.0731 & 0.6259 & $0.9 \mid 45$ & $<.0001$ \\
\hline
\end{tabular}

not initially targeted (Bandura, 1977). Future interventions may focus on providing autonomy support as a means of improving self-efficacy (Lee et al., 2019). Successful performance of a behavior is positively correlated with improved self-efficacy (Glanz et al., 2014). A recent qualitative study of
14 heart transplant patients one-year post-transplant, reinforced the large impact performance accomplishment has on self-efficacy expectations (Almgren et al., 2017). Other potential mechanisms that influence self-efficacy expectations include verbal persuasion or encouragement, role 
Table 4. Clinical and Sociodemographic Determinants of Self-care Management.

\begin{tabular}{|c|c|c|c|c|c|c|}
\hline \multirow{2}{*}{$\frac{\text { Variable }}{\text { Gender }}$} & \multirow{2}{*}{$\begin{array}{r}\text { Direction } \\
\text { Female versus Male }\end{array}$} & \multirow{2}{*}{$\begin{array}{r}\text { Estimate } \\
0.9009\end{array}$} & \multirow{2}{*}{$\begin{array}{c}\begin{array}{c}\text { Standard } \\
\text { Error }\end{array} \\
2.8115\end{array}$} & \multicolumn{2}{|c|}{ 95\% Confidence Limits } & \multirow{2}{*}{$\begin{array}{l}\operatorname{Pr}>|t| \\
0.7490\end{array}$} \\
\hline & & & & -4.6465 & 6.4483 & \\
\hline Age & Age $<60$ versus Age $\geq 60$ & $-|.980|$ & 3.0354 & -7.9691 & 4.0089 & 0.5150 \\
\hline Ethnicity & White/Caucasian versus Others & $-1.736 \mid$ & 3.0051 & -7.6655 & 4.1933 & 0.5642 \\
\hline Income & Low versus Adequate/High & 6.2312 & 3.7167 & -1.1021 & 13.5645 & 0.0953 \\
\hline Years from the diagnosis & $<10$ years versus $\geq 10$ years & -1.5953 & 3.0045 & -7.5235 & 4.3328 & 0.5961 \\
\hline Education & $\begin{array}{l}\text { High school or lower versus } \\
\text { College or Higher }\end{array}$ & 3.1156 & 3.2700 & -3.3364 & 9.5676 & 0.3420 \\
\hline Medications & No insulin versus Insulin & -1.5484 & 3.7227 & -8.8936 & 5.7967 & 0.6779 \\
\hline Self-care confidence & & 0.6772 & 0.0662 & 0.5466 & 0.8077 & $<.0001$ \\
\hline
\end{tabular}

modeling, and improved physiological feedback (Bandura, 1977; Glanz et al., 2014).

\section{Limitations}

This secondary data analysis was limited by the available original study variables and may not have measured other clinical and sociodemographic factors potentially associated with diabetes self-care. For example, higher levels of diabetes distress and high family barriers to self-management have been associated with decreased self-efficacy (Rosland et al., 2010; Wardian \& Sun, 2014). In contrast, diabetes selfcare behaviors such as exercise and healthy diet are related to higher self-efficacy (Wardian \& Sun, 2014). Also, the sample was composed of participants recruited in different settings, some hospitalized for acute care and some in a community setting. While the study was conducted in the US, our sample characteristics are similar to those reported internationally for chronically ill patients, supporting generalizability of our results. Finally, we used a psychometrically sound tool to measure self-care maintenance, monitoring, management and confidence in the target population (Ausili et al., 2017a, 2019).

\section{Conclusion}

For people with T2DM, self-care is key for the management of their illness and the improvement of their outcomes. Self-care is influenced by clinical and socio-demographic determinants and knowing these can help clinicians identify people at risk of performing low levels of self-care. Our findings show self-efficacy as a powerful determinant of self-care maintenance, self-care monitoring, and selfcare management. This is relevant because the role of selfefficacy in T2DM remains unclear (Resnick, 2013), although an increasing number of studies tend to assign a key mediating role to it (Ausili et al., 2018; Caruso et al., 2019; Elissen et al., 2017; Jiang et al., 2019; McEwen et al., 2017; Tan et al., 2018). Therefore, future studies will need to better explore this relation. Furthermore, as self-efficacy is a modifiable determinant, future research should test interventions aimed at improving self-care through the enhancement of self-efficacy.

\section{Declaration of Conflicting Interests}

The author(s) declared no potential conflicts of interest with respect to the research, authorship, and/or publication of this article.

\section{Funding}

The author(s) received no financial support for the research, authorship, and/or publication of this article.

\section{ORCID iDs}

Michela Luciani (iD https://orcid.org/0000-0001-7598-5658

Paola Rebora (iD https://orcid.org/0000-0003-0606-5852

Michael Stawnychy iD https://orcid.org/0000-0003-0710-7639

Davide Ausili (iD https://orcid.org/0000-0001-5212-6463

\section{References}

Alberti, K. G., \& Zimmet, P. Z. (1998). Definition, diagnosis and classification of diabetes mellitus and its complications. Part 1: Diagnosis and classification of diabetes mellitus provisional report of a WHO consultation. Diabetic Medicine, 15(7), 539-553. https://doi.org/10.1002/(SICI)1096-9136(199807) 15:7<539::AID-DIA668>3.0.CO;2-S

Almgren, M., Lennerling, A., Lundmark, M., \& Forsberg, A. (2017). Self-efficacy in the context of heart transplantation A new perspective. Journal of Clinical Nursing, 26(19-20), 3007-3017. https://doi.org/10.1111/jocn. 13647

Ausili, D., Barbaranelli, C., \& Riegel, B. (2019). Generalizability of the self-care of diabetes inventory across cultures and languages: Italy and the United States. Evaluation \& the Health Professions, 43(1), 41-49. https://doi.org/10.1177/0163278719840689

Ausili, D., Barbaranelli, C., Rossi, E., Rebora, P., Fabrizi, D., Coghi, C., Luciani, M., Vellone, E., Di Mauro, S., \& Riegel, B. (2017a). Development and psychometric testing of a theorybased tool to measure self-care in diabetes patients: The selfcare of diabetes inventory. BMC Endocrine Disorders, 17(1), 66. https://doi.org/10.1186/s12902-017-0218-y

Ausili, D., Bulgheroni, M., Ballatore, P., Specchia, C., Ajdini, A., Bezze, S., Di Mauro, S., \& Genovese, S. (2017b). Self-care, 
quality of life and clinical outcomes of type 2 diabetes patients: An observational cross-sectional study. Acta Diabetologica, 54(11), 1001-1008. https://doi.org/10.1007/s00592-017$1035-5$

Ausili, D., Rossi, E., Rebora, P., Luciani, M., Tonoli, L., Ballerini, E., Androni, S., Vellone, E., Riegel, B., \& Di Mauro, S. (2018). Socio-demographic and clinical determinants of self-care in adults with type 2 diabetes: A multicentre observational study. Acta Diabetologica, 55(7), 691-702. https://doi.org/10.1007/ s00592-018-1135-x

Baig, A. A., Benitez, A., Quinn, M. T., \& Burnet, D. L. (2015). Family interventions to improve diabetes outcomes for adults. Annals of the New York Academy of Sciences, 1353(1), 89-112. https://doi.org/10.1111/nyas. 12844

Bandura, A. (1977). Self-efficacy: Toward a unifying theory of behavioral change. Psychological review, 84(2), 191-215. https://www.ncbi.nlm.nih.gov/pubmed/847061

Bommer, C., Heesemann, E., Sagalova, V., Manne-Goehler, J., Atun, R., Barnighausen, T., \& Vollmer, S. (2017). The global economic burden of diabetes in adults aged 20-79 years: A costof-illness study. The Lancet Diabetes \& Endocrinology, 5(6), 423-430. https://doi.org/10.1016/S2213-8587(17)30097-9

Bonner, T., Foster, M., \& Spears-Lanoix, E. (2016). Type 2 diabetes-related foot care knowledge and foot self-care practice interventions in the United States: A systematic review of the literature. Diabetic Foot \& Ankle, 7. https://doi.org/10.3402/ dfa.v7.29758

Caruso, R., Rebora, P., Dellafiore, F., Fabrizi, D., Riegel, B., Ausili, D., \& Di Mauro, S. (2019). Clinical and socio-demographic determinants of inadequate self-care in adults with type 1 diabetes mellitus: The leading role of self-care confidence. Acta Diabetologica, 56(2), 151-161. https://doi.org/10.1007/ s00592-018-1259-Z

Clark, M. L., \& Utz, S. W. (2014). Social determinants of type 2 diabetes and health in the United States. World Journal of Diabetes, 5(3), 296-304. https://doi.org/10.4239/wjd.v5.i3.296

Elissen, A. M. J., Hertroijs, D. F. L., Schaper, N. C., Bosma, H., Dagnelie, P. C., Henry, R. M., Van Der Kallen, C. J., Koster, A., Schram, M. T., Stehouwer, C. D. A., Schouten, J. S. A. G., Berendschot, T. T. J. M., \& Ruwaard, D. (2017). Differences in biopsychosocial profiles of diabetes patients by level of glycaemic control and health-related quality of life: The maastricht study. PLoS One, 12(7). https://doi.org/10.1371/journal. pone. 0182053

Eller, L. S., Lev, E. L., Yuan, C., \& Watkins, A. V. (2018). Describing self-care self-efficacy: Definition, measurement, outcomes, and implications. International Journal of Nursing Knowledge, 29(1), 38-48. https://doi.org/10.1111/2047-3095.12143

Glanz, K., Rimer, B. K., \& Viswanath, K. (2014). Health behavior: Theory, research, and practice. Wiley. http://ebookcentral.proquest.com/lib/upenn-ebooks/detail.action?docID $=2082957$

Hardigan, T., Ward, R., \& Ergul, A. (2016). Cerebrovascular complications of diabetes: Focus on cognitive dysfunction. Clinical Science (London, England: 1979), 130(20), 1807-1822. https:// doi.org/10.1042/CS20160397

International Diabetes Federation. (2017). IDF Diabetes Atlas (8th ed.). www.diabetesatlas.org.

Irani, E., Moore, S. E., Hickman, R. L., Dolansky, M. A., Josephson, R. A., \& Hughes, J. W. (2019). The contribution of living arrangements, social support, and self-efficacy to selfmanagement behaviors among individuals with heart failure: A path analysis. The Journal of Cardiovascular Nursing, 34(4), 319-326. https://doi.org/10.1097/JCN.0000000000000581

Jiang, X., Wang, J., Lu, Y., Jiang, H., \& Li, M. (2019). Selfefficacy-focused education in persons with diabetes: A systematic review and meta-analysis. Psychology Research and Behavior Management, 12, 67-79. https://doi.org/10.2147/ PRBM.S192571

Karimy, M., Araban, M., Zareban, I., Taher, M., \& Abedi, A. (2016). Determinants of adherence to self-care behavior among women with type 2 diabetes: An explanation based on health belief model. Medical Journal of the Islamic Republic of Iran, 30, 368. http://www.ncbi.nlm.nih.gov/pmc/articles/PMC4972051/

Koponen, A. M., Simonsen, N., \& Suominen, S. (2017). Determinants of physical activity among patients with type 2 diabetes: The role of perceived autonomy support, autonomous motivation and self-care competence. Psychology, Health \& Medicine, 22(3), 332-344. https://doi.org/10.1080/13548506. 2016.1154179

Lee, A. A., Piette, J. D., Heisler, M., Janevic, M. R., \& Rosland, A. M. (2019). Diabetes self-management and glycemic control: The role of autonomy support from informal health supporters. Health Psychology, 38(2), 122-132. https://doi.org/10.1037/ hea0000710

McEwen, M. M., Pasvogel, A., Murdaugh, C., \& Hepworth, J. (2017). Effects of a family-based diabetes intervention on behavioral and biological outcomes for Mexican American adults. Diabetes Educator, 43(3), 272-285. https://doi. org/10.1177/0145721717706031

Osokpo, O., \& Riegel, B. (2019). Cultural factors influencing selfcare by persons with cardiovascular disease: An integrative review. International Journal of Nursing Studies, 103383. https://doi.org/10.1016/j.ijnurstu.2019.06.014

Powers, M. A., Bardsley, J., Cypress, M., Duker, P., Funnell, M. M., Fischl, A. H., Maryniuk, M. D., Siminerio, L., \& Vivian, E. (2017). Diabetes self-management education and support in Type 2 diabetes: A joint position statement of the American diabetes association, the American association of diabetes educators, and the academy of nutrition and dietetics. The Diabetes Educator, 43(1), 40-53. https://doi. org/10.1177/0145721716689694

Resnick, B. (2013). Theory of self-efficacy. In M. J. Smith \& P. R. Liehr (Eds.), Middle Range Theory for Nursing (3rd ed., pp. 197-223). Springer Publishing Company. http://ebookcentral. proquest.com/lib/upenn-ebooks/detail.action?docID=1182694

Riegel, B., Jaarsma, T., Lee, C. S., \& Stromberg, A. (2018). Integrating symptoms into the middle-range theory of self-care of chronic illness. ANS. Advances in Nursing Science. https:// doi.org/10.1097/ANS.0000000000000237

Riegel, B., Jaarsma, T., \& Strömberg, A. (2012). A middle-range theory of self-care of chronic illness. ANS. Advances in Nursing Science, 35(3), 194-204. https://doi.org/10.1097/ANS.0b013 e318261b1ba

Rosland, A. M., Heisler, M., Choi, H. J., Silveira, M. J., \& Piette, J. D. (2010). Family influences on self-management among functionally independent adults with diabetes or heart failure: Do family members hinder as much as they help? Chronic Illness, 6(1), 22-33. https://doi.org/10.1177/1742395309354608 
Scollan-Koliopoulos, M., Bleich, D., Rapp, K. J., Wong, P., Hofmann, C. J., \& Raghuwanshi, M. (2013). Health-related quality of life, disease severity, and anticipated trajectory of diabetes. The Diabetes Educator, 39(1), 83-91. https://doi. org/10.1177/0145721712467697

Song, M. (2010). Diabetes mellitus and the importance of self-care. The Journal of Cardiovascular Nursing, 25(2), 93-98. https:// doi.org/10.1097/JCN.0b013e3181c5a364

Song, M., Ratcliffe, S. J., Tkacs, N. C., \& Riegel, B. (2012). Self-care and health outcomes of diabetes mellitus. Clinical Nursing Research, 21(3), 309-326. https://doi.org/10.1177 $/ 1054773811422604$

Tan, C. C. L., Cheng, K. K. F., Hwang, S. W., Zhang, N., Holydard, E., \& Wang, W. (2018). Effect of a diabetes self-efficacy enhancing program on older adults with type 2 diabetes: A randomized controlled trial. Clinical Nursing Research. https:// doi.org/10.1177/1054773818792480

Walker, R. J., Gebregziabher, M., Martin-Harris, B., \& Egede, L. E. (2014). Independent effects of socioeconomic and psychological social determinants of health on self-care and outcomes in Type 2 diabetes. General Hospital Psychiatry, 36(6), 662-668. https://doi.org/10.1016/j.genhosppsych.2014.06.011

Wardian, J., \& Sun, F. (2014). Factors associated with diabetesrelated distress: Implications for diabetes self-management. Social Work in Health Care, 53(4), 364-381. https://doi.org/10 $.1080 / 00981389.2014 .884038$

Wichit, N., Mnatzaganian, G., Courtney, M., Schulz, P., \& Johnson, M. (2017). Randomized controlled trial of a family-oriented self-management program to improve self-efficacy, glycemic control and quality of life among Thai individuals with Type 2 diabetes. Diabetes Research and Clinical Practice, 123, 37-48. https://doi.org/10.1016/j.diabres.2016.11.013

\section{Author Biographies}

Michela Luciani, RN, MSN, $\mathrm{PhD}$, is research fellow at the Department of Medicine and Surgery, University of Milano Bicocca, Monza, Italy.

Emanuela Rossi, $\mathrm{PhD}$, is research fellow at the Centre of Biostatistics for Clinical Epidemiology, Department of Medicine and Surgery, University of Milano - Bicocca, Monza, Italy.

Paola Rebora, $\mathrm{PhD}$, is an assistant professor in Medical Statistics at the Centre of Biostatistics for Clinical Epidemiology, Department of Medicine and Surgery, University of Milano - Bicocca, Monza, Italy.

Michael Stawnychy, MSN, CRNP, PhD, is a doctoral student at the Robert Wood Johnson Foundation Future of Nursing Scholar, School of Nursing, University of Pennsylvania, Philadelphia, PA, USA.

Davide Ausili, RN, MSN, PhD, is an assistant professor in Nursing Science at the Department of Medicine and Surgery, University of Milano - Bicocca, Monza, Italy.

Barbara Riegel, RN, PhD, FAHA, FAAN, is full professor of Nursing at the School of Nursing, University of Pennsylvania, Philadelphia, PA, USA. 